\title{
Effects of Continuous D-Amphetamine and Phencyclidine Administration on Social Behaviour, Stereotyped Behaviour, and Locomotor Activity in Rats
}

Frank Sams-Dodd, Ph.D.

D-amphetamine (AMPH) and phencyclidine $(P C P)$ can induce a model psychosis that mimic the positive symptoms of schizophrenia, but only PCP also mimics the negative symptoms. Recent studies in the rat social interaction test have shown that $P C P$, and not $A M P H$, induce social withdrawal following single and repeated injections, and this effect may, therefore, be used to model negative symptoms. However, an AMPH psychosis is usually only seen after a prolonged period of repeated injections or continuous administration for 3-5 days of high doses of AMPH. It is, therefore, possible that in these studies, $A M P H$ was administered at insufficient levels in rats, and this may explain its lack of effect. The present study has determined the effects of continuous administration of
AMPH (23 to $94 \mu \mathrm{mol} / \mathrm{kg} /$ day; 4.2 to $17 \mathrm{mg} / \mathrm{kg} /$ day) and PCP (18 to $107 \mu \mathrm{mol} / \mathrm{kg} /$ day; 5.0 to $30 \mathrm{mg} / \mathrm{kg} /$ day) in rats after five days of infusion in the social interaction test and after 6-7 days in standard activity cages. The study found that AMPH and PCP dose-dependently induced stereotyped behaviour and locomotor hyperactivity, behaviours believed to be related to positive symptoms, and that only PCP induced social withdrawal. These findings confirm previous studies that only PCP and not AMPH induce deficits in the social behaviour of rats.

[Neuropsychopharmacology 19:18-25, 1998] (C) 1998 American College of Neuropsychopharmacology. Published by Elsevier Science Inc.
KEY WORDS: Amphetamine; Negative symptoms;

Phencyclidine; Positive symptoms; Rat; Social behaviour

A number of clinical studies have reported that $\mathrm{d}$-amphetamine (AMPH) and phencyclidine (PCP) can induce a psychosis that resemble schizophrenia (Bell 1965; Snyder 1973; Siegel 1978). Both AMPH and PCP can mimic the hallucinations and paranoia that are characteristic of the positive symptoms, but only PCP can also mimic the social withdrawal and blunted affect

From Pharmacological Research, H. Lundbeck A/S, Valby, Denmark.

Address correspondence to: Dr. Frank Sams-Dodd, Pharmacological Research, H. Lundbeck A/S, Ottiliavej 9, DK-2500 Valby, Denmark.

Received May 29, 1997; revised September 19, 1997; accepted September 25, 1997. that are characteristic of the negative symptoms of schizophrenia (Javitt and Zukin 1991; Meltzer 1991). The resemblance in many aspects between an AMPH and a PCP psychosis and schizophrenia has made these compounds the primary psychotomimetic model agents in schizophrenia research (Javitt and Zukin 1991; Lyon 1991). In rats both compounds induce behaviours such as locomotor hyperactivity, stereotyped behaviour and disruption of pre-pulse startle response (Geyer et al. 1990; Jackson et al. 1994), which are believed to correspond to certain aspects of the positive symptoms. Recent studies have also compared AMPH and PCP in the social interaction test and it was found that only $\mathrm{PCP}$, and not AMPH, consistently affected the social behaviour (Guy and Gardner 1985; Corbett et al. 1995; Sams-Dodd 1995a, 1996). A key component of the nega- 
tive symptoms is social withdrawal, and these findings have thus suggested that social withdrawal in rats may be related to the PCP-induced negative symptoms in man and that this may be a potential animal model of negative symptoms.

One particular issue of concern in these studies is, however, that the behavioural effects of AMPH were only determined following single or repeated daily injections for up to five days. Clinical observation have shown that a AMPH psychosis can occur following a single high dose of $\mathrm{AMPH}$, but usually it is only seen after a prolonged period (hours to days) of continuous abuse of high doses of AMPH (Connell 1958; Angrist and Gershon 1970; Griffith et al. 1972; Bell 1973). This is in contrast to the PCP psychosis, which normally occurs in 20 to 40 min following single or repeated administration (Greifenstein et al. 1958; Davies and Beech 1960). Several studies have demonstrated that rats also require repeated or continuous administration of AMPH for the appearance of abnormal behaviours. Gambil and Kornetsky (1976) have reported that increasing doses of AMPH up to $8 \mathrm{mg} / \mathrm{kg}$ for several weeks were necessary to induce behavioural changes that had some similarity to an amphetamine psychosis. Ellison et al. (1978) and Gately et al. (1987), using continuous infusion of AMPH at doses of $81 \mu \mathrm{mol} / \mathrm{kg} /$ day $(11 \mathrm{mg} / \mathrm{kg} /$ day $)$ and 115 $\mu \mathrm{mol} / \mathrm{kg} /$ day $(15.6 \mathrm{mg} / \mathrm{kg} /$ day), found that infusion for four to five days was necessary to induce similar behavioural changes. It is, therefore, possible that the limited effects of AMPH on the social behaviour in rats correlate with the fact that AMPH was administered as single daily injections for only up to five days, and this may have been insufficient to induce a psychotic state.

The present study attempts to address this issue by determining the dose-response for continuous infusion of $\mathrm{AMPH}$ and PCP in the social interaction test after five days of administration, and in standard activity cages after six or seven days of administration. The average daily doses for AMPH were 23, 45, and $94 \mu \mathrm{mol} /$ $\mathrm{kg} /$ day $(4.2,8.4$, and $17 \mathrm{mg} / \mathrm{kg} /$ day, respectively) and for PCP 18, 36, 71, and $107 \mu \mathrm{mol} / \mathrm{kg} /$ day $(5.0,10,20$, and $30 \mathrm{mg} / \mathrm{kg} /$ day, respectively). Higher doses were not included because the compounds would attain toxic properties. Comparison to previous studies using continuous infusion of AMPH in rats (Ellison et al. 1978; Gately et al. 1987) indicates that this duration of infusion, as well as this dose range for AMPH should be sufficient to induce psychotic-like behaviors in the rat. In the social interaction test the rats are tested under low-light conditions during their nocturnal period to favour high-base line levels of social behaviour, whereby the test becomes highly sensitive to druginduced disturbances of this behaviour. Pairs of identically treated rats, that are unfamiliar to each other, are placed in dark, unknown arena for $10 \mathrm{~min}$ and their behavior is quantified by automated analysis system that tracks the rats' movements and is accompanied by manual ratings of stereotyped behaviour. In a previous study it has been demonstrated that the level of social proximity measured by the automated system correspond to the level of social behaviour recorded by a human observer (Sams-Dodd 1995b). In the locomotor activity test the rats are tested for $120 \mathrm{~min}$ in a brightly illuminated room to suppress the baseline activity level of vehicle treated rats in order to increase the sensitivity of the test to drug-induced locomotor hyperactivity. The present treatment regime should most likely induce a state in rats that resemble a psychosis, and it should thereby be possible to compare the behavioural effects of AMPH and PCP in rats to the psychotomimetic properties of these compounds in man.

\section{MATERIALS AND METHODS}

\section{Animals}

Male Wistar rats (Charles River, Germany) weighing 320-420 grams at the time of testing were used for these experiments. They were housed in groups of three in Macrolon type III cages in an animal room at $21 \pm 2^{\circ} \mathrm{C}$ with a relatively humidity of $55 \pm 5 \%$, air exchange (16 times/hr) and kept in a reversed 12h:12h light/dark cycle (light on 1800-0600 h). They had free access to water and commercial food pellets throughout the study. The methods and procedures of the present study were approved by the Danish Committee on Animal Welfare.

\section{Drugs and Drug Administration}

For continuous infusion of d-amphetamine (d-amphetamine $\cdot 1 / 2$ sulphate; mol. wt. 184.3 ; Nomeco, Copenhagen, dissolved in $0.1 \%$ sodium bisulphate solution in $\mathrm{N}_{2}$-aerated distilled water) or phencyclidine (phencyclidine, $\mathrm{HCl}$; mol. wt. 280.5; synthesised at $\mathrm{H}$. Lundbeck A/S, Valby Denmark, dissolved in saline) and their respective vehicle solutions, osmotic minipumps (Model 2ML2, Alzet Corp.) were filled $24 \mathrm{hr}$ prior to implantation and placed in a saline water bath at $37^{\circ} \mathrm{C}$. Rats were anaesthetised (3-3.5\% halothane in $30 / 70 \% \mathrm{O}_{2} / \mathrm{N}_{2} \mathrm{O}$ ), and an area on the back of the rat was shaved and cleaned with a chlorhexidine solution $(0.5 \%$ solution of chlorhexidine acetate, Nomeco, Copenhagen, in 10\% ethanol). A small incision was made, a pocket beneath the skin was formed and the minipump was placed inside the pocket in each rat. The incision was sutured, cleaned with chlorhexidine, and sprayed with Wound Plast. The rats were returned to their home cage and in 30-60 min they had recovered and were active.

The actual dosages that the rats received were estimated from the concentrations of AMPH or PCP in the osmotic minipumps, the average weight of the rats at the time of testing, and the average pumping rate of the 
minipumps (specified by manufacturer). The dosages were for AMPH 23, 45, and $94 \mu \mathrm{mol} / \mathrm{kg} /$ day $(4.2,8.4$, and $17 \mathrm{mg} / \mathrm{kg} /$ day, respectively) and for PCP 18, 36, 71 , and $107 \mu \mathrm{mol} / \mathrm{kg} /$ day $(5.0,10,20$, and $30 \mathrm{mg} / \mathrm{kg} /$ day, respectively).

\section{Experimental Procedure}

After arrival, the rats were randomly assigned to groups of three and placed in a reversed daylight cycle for three weeks. The rats were housed with the same cage mates at all times and all rats within a given cage received identical treatment. Two weeks after arrival, half of the rats within each treatment group were dyed with hair colour on the rear part of the body. Approximately 2.5 weeks after arrival the rats received implantation with osmotic minipumps (Day 0). On Day 5 they were tested in the social interaction test and on Day 6 or 7 they were tested in the motility test. Following the last behavioural test the pumps were removed and checked to ensure that they had functioned properly. The doseresponse for AMPH estimated in this study is based on two separate experiments to ensure replicability.

\section{Social Interaction Test}

The general design of the model was adapted from File (1988) and has previously been described in detail (Sams-Dodd 1995b, 1996). The test was performed in an open arena $(\mathrm{l}, \mathrm{w}, \mathrm{h}: 150 \times 100 \times 40 \mathrm{~cm})$ with bedding of grey gravel. The gravel had been exposed to other rats before testing to provide a constant odour level in the arena. The behaviour of the rats was recorded by a video camera (Cohou model 4722-2000 with Ernitec 6 $\mathrm{mm} / 1.2$ lens) that was placed above the arena and was connected to a S-VHS video cassette recorder. Lighting in the room consisted only of dark-red light (25 Watt bulbs) and was diffuse to minimise shadows in the arena. Three arenas were run in parallel and were started at the same time.

The white and black rats were placed in the experimental room the day before testing. On the day of testing all rats were weighed. One white and one black rat, that had received identical treatment and that were unfamiliar to each other, were placed simultaneously into the unfamiliar arena $80-90 \mathrm{~cm}$ apart. Their behaviour was video filmed for $10 \mathrm{~min}$ whereafter the rats were returned to their home cages. Testing in the social interaction test was conducted between $0800 \mathrm{~h}$ and $1400 \mathrm{~h}$. First, each 10 min observation period on the videotapes was analysed off-line by the EthoVision ${ }^{\circledR}$ programme (version 1.80, Noldus Information Technologies, b.v.). The arena was scanned 3.1 times per sec by the programme and for each scanning the positions of the rats were determined. These coordinates were subsequently related to actual distances in the arena by a calibration of the programme to the dimensions of the arena. This analysis resulted in a track record for each rat that contained a complete record of the rat's movement pattern in the arena during the observation period, and this track record was analysed for the parameters described below.

Distance Travelled. Total distance travelled during an observation period.

Percent Time in Central Zone. Percentage of the $10 \mathrm{~min}$ observation period spend in the central zone by each rat. The arena was divided into a central and a peripheral zone that covered $33 \%$ and $66 \%$ of the arena, respectively, and measured the exploratory pattern of the rats in the arena.

Active and Passive Social Interaction. Social interaction was defined as a maximal distance of $20 \mathrm{~cm}$ between the rats, and it was subsequently divided into an active and a passive component for each rat based upon whether the rat actively moved or was inactive (see Sams-Dodd (1996) for details on the calculation of this parameter).

Secondly, stereotyped behaviour and ataxia were rated off-line by a trained observer who was blind to the treatment paradigm. Each recording on the videotapes was viewed for $60 \mathrm{sec}$ halfway through the $10 \mathrm{~min}$ observation period, and each rat was given a separate score for PCP stereotyped behaviour, ataxia, and AMPH stereotyped behaviour. The score assigned for each behaviour category was determined as the highest level of stereotype or ataxia consistently observed during the rating period. A score of ataxia was only given if the rats moved sufficiently during the rating period to allow a reliable estimation. The rating scales are given below. The scales for PCP stereotyped behaviour and ataxia are after Castellani and Adams (1981).

PCP Stereotyped Behaviour. This is classified as: (0), Stationary, little or no movement; (1), Active, occasional to frequent movement; (2), Active with episodes of repetitive forward head searching (the rat walked forward in a stereotyped manner along the periphery of the arena without engaging in other behaviors); (3), Continuous forward head searching; (4), Frequent repetitive rearing, side-to-side weaving or turning; (5), Episodes of rapid jerky side-to-side, circular or dorsoventral head movements (the rat was usually stationary).

Ataxia. This is classified as: (0), Co-ordinated movements; (1) Mild staggering, swaying locomotion and rearing without falling; (2), Moderate uncoordinated movements with occasional to frequent falling; (3), Unable to support weight, crawling locomotion only; (4), No locomotion, lying on side or abdomen. 
Amphetamine Stereotyped Behaviour. This is classified as: (0), No repetitive head movements; (1), Weak repetitive side-to-side head movements; (2), Strong repetitive side-to-side head movements; (3), Stationary stereotyped behaviour with strong side-to-side or circular head movements.

\section{Motility Test}

Locomotor activity was measured for $120 \mathrm{~min}$ in Macrolon type III $(\mathrm{l}, \mathrm{w}, \mathrm{h} ; 37 \times 22 \times 19 \mathrm{~cm})$ animal cages with a bedding of wood shavings in a brightly lit room. Four sets of equally spaced photo diodes registered movements in the longitudinal direction of individual cages as the number of times the infrared light beams were interrupted. The activity counts would not increment if the same light beam was interrupted twice or more in a row without activation of other beams, thus preventing repetitive stationary movements from affecting the activity counts. Registration and timing of locomotor activity was fully automated (custom-designed hardware and software). Testing was conducted between 0800 and 1400 hrs.

\section{Data and Statistical Analysis}

One-way ANOVA with Fishers LSD post hoc test was used (two-tailed) for statistical analysis of all the behavioural parameters. The scores based on rating scales, which are of an ordinal type, were ranked (Huitema
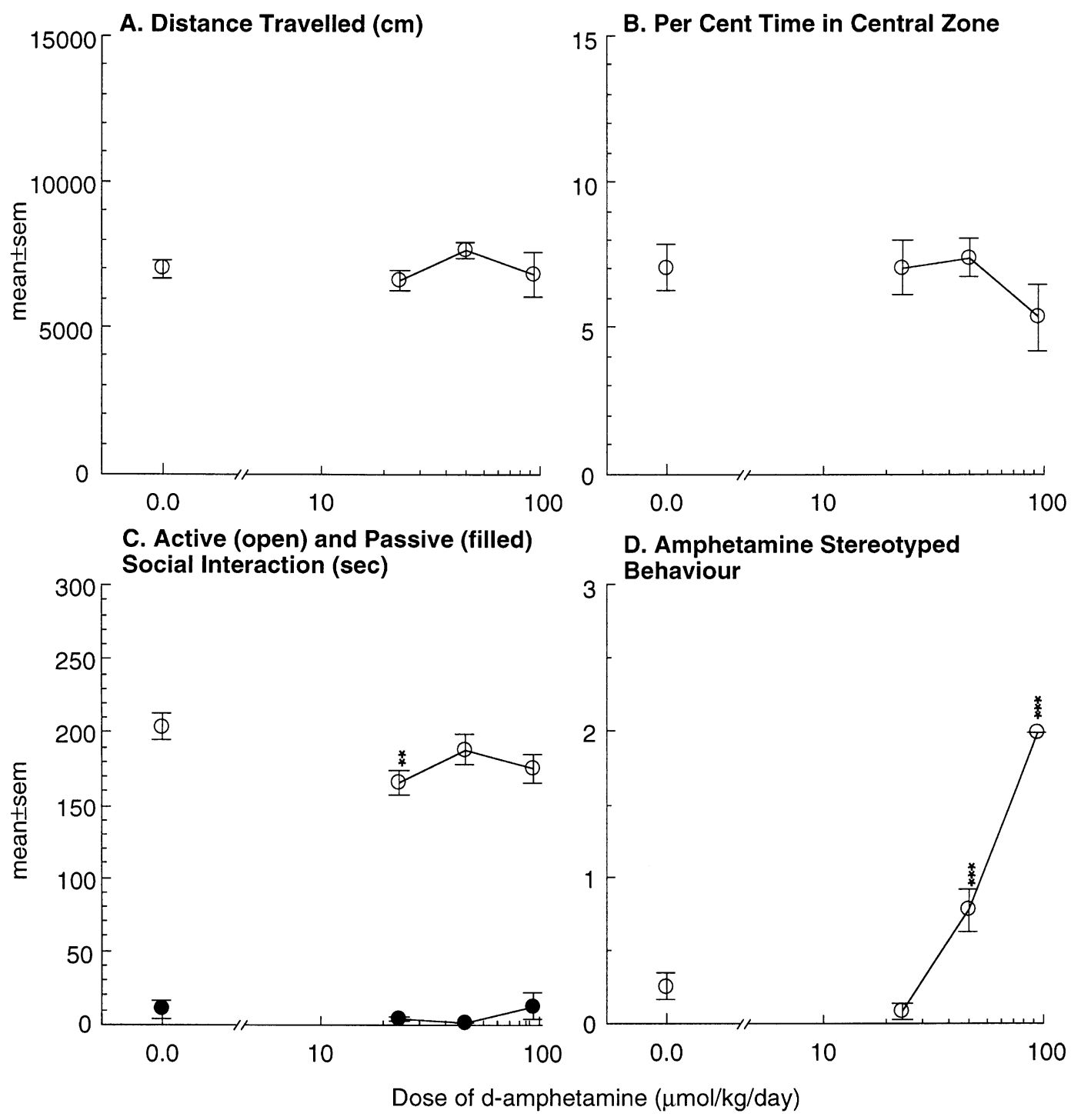

Figure 1. Dose-response curve for continuous administration of d-amphetamine for five days on the behaviour of rats in the social interaction test. Each treatment group included 12 pairs of rats. Asterisks indicate level of significance relative to the vehicle group and are based on an ANOVA test with a Fishers LSD post-hoc test (two-tailed): $\left({ }^{*}\right) P<.05 ;\left({ }^{* *}\right) P<.001$; $\left.{ }^{* * *}\right) P<.001$. 
1980), and the activity counts were log-transformed prior to statistical analysis. All data are presented as means with standard error of mean (sem) and the statistical analysis was performed with Systat v. 5.2 (Macintosh version).

\section{RESULTS}

The rats receiving AMPH dose-dependently developed stationary stereotyped behaviours and oral movements following implantation of the osmotic minipumps. However, they developed tolerance to some of these effects over the next 2-3 days and the stationary behaviours gradually disappeared. On Day 5 the rats were tested in the social interaction test and the continuous administration of AMPH had only very limited effects on their behaviour, except for pronounced stereotyped behaviour head movements and occasional stationary stereotyped behaviours (Figure 1). The locomotor activity, i.e., distance travelled, $(F(3,76)=1.6 ; P=\mathrm{NS})$, per cent time in central zone $(F(3,76)=0.7 ; P=\mathrm{NS})$, and passive social interaction $(F(3,76)=1.4 ; P=\mathrm{NS})$ did not demonstrate any significant effects of the drug treatment, and active social interaction was only slightly decreased at the lowest dose $(F(3,76)=3.2 ; P<.05)$. In contrast to these minimal effects the rats demonstrated a dosedependent increase in AMPH stereotyped behaviour $(F(3,76)=28.4 ; P<.001)$. On Day 6 or 7 the rats were tested in the motility test (Figure 2) and here AMPH induced dose-dependent increases in locomotor activity $(F(3,84)=15.1 ; P<.001)$.
Continuous infusion of PCP (Figure 3) at 18, 36, 71, and $107 \mu \mathrm{mol} / \mathrm{kg} /$ day $(5.0,10,20$, and $30 \mathrm{mg} / \mathrm{kg} /$ day, respectively) on Day 5 dose-dependently induced increases in distance travelled $(F(4,85)=29.1 ; P<.001)$, stereotyped behaviour $(F(4,85)=116.4 ; P<.001)$, and ataxia $(F(4,85)=110.1 ; P<.001)$, and decreases in per cent time in central zone $(F(4,85)=11.2 ; P<.001)$ and active social interaction $(F(4,85)=50.5 ; P<.001)$, but did not affect passive social interaction $(F(4,85)=P<$ NS). In the motility test on Day 6 PCP dose-dependently induced increases in locomotor activity $(F(4,85)=15.1$; $P<.001)$. The reduction in distance travelled and activity score at the highest dose was caused by the pronounced ataxia which inhibited the movements of the rats.

\section{DISCUSSION}

The present study has demonstrated that continuous infusion of AMPH or PCP dose-dependently induces stereotyped behaviour and locomotor hyperactivity in rats, and that PCP, and not AMPH, also induces social withdrawal. The findings for AMPH are consistent with previously reported effects of acute and subchronic AMPH in the social interaction test (Guy and Gardner 1985; Corbett et al. 1995; Sams-Dodd 1995a, 1996) and studies of stereotyped behaviour and locomotor activity following acute, chronic, and continuous AMPH administration (e.g., Nielsen 1981; Robinson and Becker 1986). Comparison to earlier studies (Gambil and Kornetsky 1976; Ellison et al. 1978; Gately et al. 1987) suggests, that the dose regime and duration of administra-

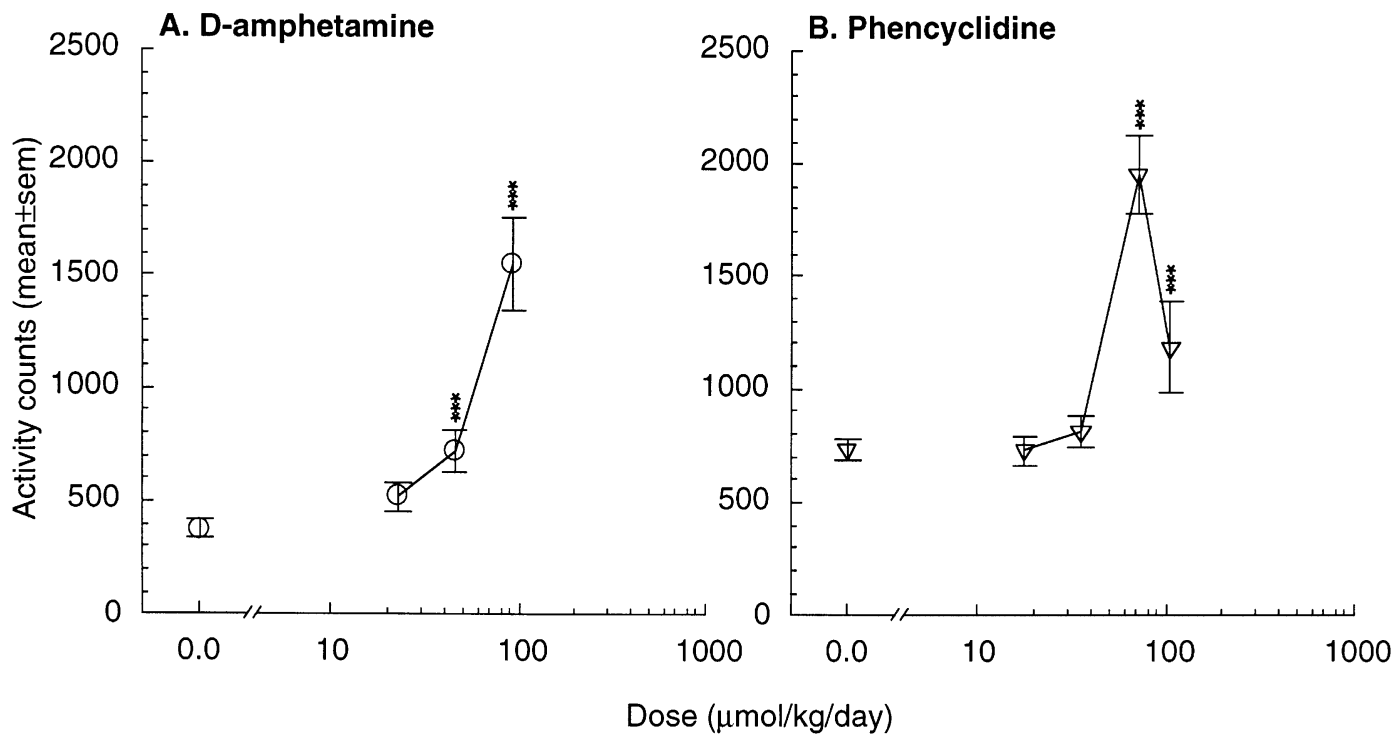

Figure 2. Dose-response curve for d-amphetamine or phencyclidine after continuous administration for six or seven days on the locomotor activity of rats in the motility test, measured over a period of $120 \mathrm{~min}$. Each treatment group include 24 rats for $\mathrm{d}$-amphetamine and 18 for phencyclidine. For explanation of symbols see Figure 1. 
tion in the present study was sufficient to produce the abnormal behaviours in rats that have been described by these authors. Therefore, it seems likely that AMPH does not induce social isolation in the rat. For PCP the findings were comparable to previous studies (SamsDodd 1995a, 1996, 1997) and the present data, thus, support the conclusion that these compounds have distinct behavioural effects on social behaviour in rats.

Several studies have demonstrated that AMPH in primates can induce social withdrawal and isolation (e.g., Scaggs and Ridley 1979; Schiörring 1997; Miczek et al. 1981; Nielsen et al. 1983) although negative findings have also been reported (Sams-Dodd and Newman 1997). For example, Schiörring (1997) have reported that even very low doses of AMPH can disrupt the motherinfant bond for several hours in green velvet monkeys, and Ellenbroek et al. (1989) have used AMPH-induced social withdrawal for the evaluation of potential antipsychotic compounds. These findings are very different from the effects of AMPH in rats and suggest that nonhuman primates respond fundamentally different to the effects of AMPH. However, the effects of AMPH in these non-human primates are to some extent in conflict with clinical observations. It has not been reported that AMPH after a single low dose should precipitate psychotic symptoms and social withdrawal in man as reported by Schiörring (1997) in the green velvet monkey, or that AMPH should induce both positive and negative symptoms in a majority of subjects. It is therefore possible that some primates are supersensitive to AMPH or that behaviours unrelated to psychotic symptoms have been observed. Another possibility is also that the AMPH-induced social isolation in monkeys, as reported by Ellenbroek et al. (1989), is partly caused by
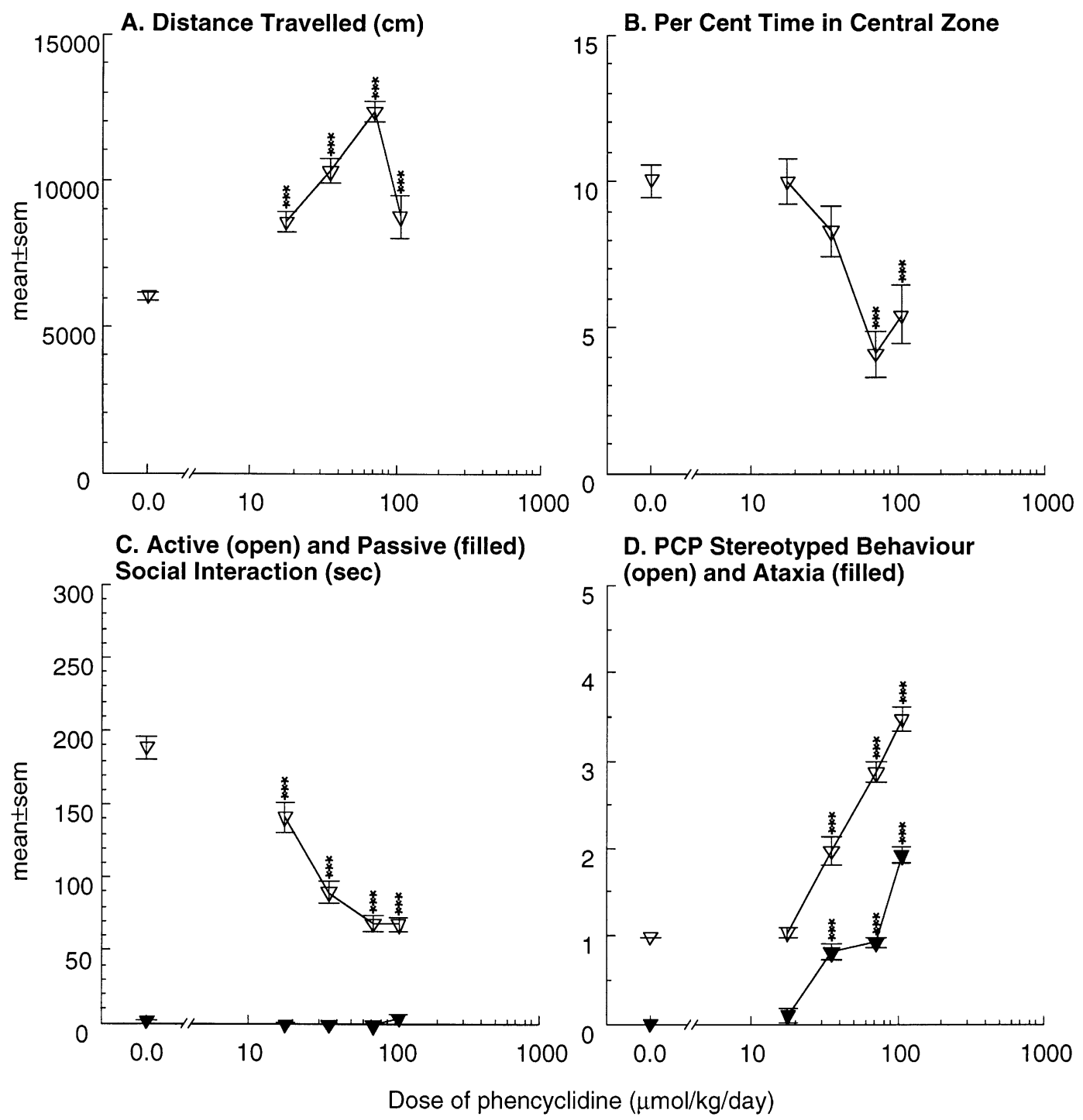

Figure 3. Dose-response curve for continuous administration of phencyclidine for five days on the behaviour of rats in the social interaction test. Each treatment group included nine pairs of rats. For explanation of symbols see Figure 1. 
the presence of pronounced stereotyped behaviours and that the monkeys simply cannot engage in social activity while performing stereotyped movements. In rats it has been possible to dissociate the effect of PCP on social behaviour from stereotyped behaviour and locomotor hyperactivity (Sams-Dodd 1996), but comparable studies have not been performed in monkeys for $\mathrm{AMPH}$ and this issue can therefore not be resolved.

In conclusion, the present study has shown that AMPH and PCP in rats following continuous administration for 5-7 days induces stereotyped behaviour and locomotor hyperactivity, but only PCP induces social withdrawal. These findings together with previous studies of AMPH and PCP in the social interaction test (Sams-Dodd 1995a, 1996) demonstrate that AMPH and PCP have very distinct effect on the social behaviour of rats, and that social withdrawal in rats may be a valid test for measuring behaviours corresponding to negative symptoms in man.

\section{ACKNOWLEDGMENTS}

I thank Ms. Marit Pedholt Gitz, Mr. Nicolai L. Steffensen, and Ms. Pi Ørum for their technical assistance in conducting these experiments, and Dr. Jørn Arnt and Mrs. Jeanette Sams-Dodd for commenting on the manuscript.

\section{REFERENCES}

Angrist BM, Gershon S (1970): The phenomenology of experimentally induced amphetamine psychosis-preliminary observations. Am J Psychiatr 2:95-107

Bell DS (1965): Comparison of amphetamine psychosis and schizophrenia. Br J Psychiatr 111:701-707

Bell DS (1973): The experimental reproduction of amphetamine psychosis. Arch Gen Psychiatr 29:35-40

Castellani S, Adams PM (1981): Acute and chronic phencyclidine effects on locomotor activity, stereotypy and ataxia in rats. Eur J Pharmacol 73:143-154

Connell PH (1958): Amphetamine psychosis. London, Chapman \& Hall

Corbett R, Camacho F, Woods AT, Kerman LL, Fishkin RJ, Brooks K, Dunn RW (1995): Antipsychotic agents antagonize non-competitive $\mathrm{N}$-methyl-d-asparate antagonistinduced behaviors. Psychopharmacology 120:67-74

Davies BM, Beech HR (1960): The effects of 1-arylcyclohexylamine (sernyl) on twelve normal volunteers. J Mental Sci 106:912-914

Ellenbroek BA, Willemen APM, Cools AR (1989): Are antagonists of dopamine $d_{1}$ receptors drugs that attenuate both positive and negative symptoms of schizophrenia? a pilot study in java monkeys. Neuropsychopharmacology 2:191-199

Ellison G, Eison MS, Huberman HS (1978): Stages of constant amphetamine intoxication: Delayed appearance of abnor- mal social behaviors in rat colonies. Psychopharmacology 56:293-299

File SE (1988): How good is social Interaction as a test of anxiety? Animal Models Psychiatr Dis 1:151-166

Gambil JD, Kornetsky C (1976): Effects of chronic d-amphetamine on social behavior of the rat: Implications for an animal model of paranoid schizophrenia. Psychopharmacology 50:215-223

Gately PF, Segal DS, Geyer MA (1987): Sequential changes in behavior induced by continuous infusion of amphetamine in rats. Psychopharmacology 91:217-220

Geyer M, Swerdlow NR, Mansbach RS, Braff DL (1990): Startle response models of sensorimotor gating and habituation deficits in schizophrenia. Brain Res Bull 25:485-498

Greifenstein FE, Yoshitake J, DeValut M, Gajewski JE (1958): A Study of 1-aryl cyclo hexyl amine for anesthesia. Anesth Analg 37:283-294

Griffith JD, Cavanaugh J, Held J, Oates JA (1972): Dextroamphetamine. Arch Gen Psychiatr 26:97-100

Guy AP, Gardner CR (1985): Pharmacological characterisation of a modified social interaction model of anxiety in the rat. Neuropsychobiol. 13:194-200

Huitema BE (1980): The analysis of covariants and alternatives. New York, Wiley \& Sons

Javitt DC, Zukin SR (1991): Recent advances in the phencyclidine model of schizophrenia. Am J Psychiatry 148: 1301-1308

Jackson DM, Johansson C, Lindgren LM, Bengtson A (1994): Dopamine receptor anatagonists block amphetamine and phencyclidine-induced motor stimulation in rats. Pharmacol Biochem Behav 41:465-471

Lyon M (1991): Animal models of mania and schizophrenia. In Willner P (ed), Behavioural Models in Psychopharmacology: Theoretical, Industrial and Clinical Perspectives. Cambridge, Cambridge University Press, pp. 253-310

Meltzer HY (1991): The mechanism of action of novel antipsychotic drugs. Schiz Bull 17:262-287

Miczek KA, Woolley J, Schlisserman S, Yoshimura H (1981): Analysis of amphetamine effects on agonistic and affiliative behavior in squirrel monkeys saimiri-sciureus. Pharmacol Biochem Behav 14:103-108

Nielsen EB (1981): Rapid decline of stereotyped behavior in rats during constant 1 week administration of amphetamine via implanted alzet osmotic mini pumps. Pharmacol Biochem Behav 15:161-166

Nielsen EB, Lyon M, Ellison G (1983): Apparent hallucinations in monkeys during around-the-clock amphetamine for seven to fourteen days. J Nerv Mental Dis 171:222-233

Robinson TE, Becker JB (1986): Enduring changes in brain and behavior produced by chronic amphetamine administration: A review and evaluation of animal models of amphetamine psychosis. Brain Res Rev 11:157-198

Sams-Dodd F (1995a): Distinct effects of d-amphetamine and phencyclidine on the social behaviour of rats. Behav Pharmacol 6:55-65

Sams-Dodd F (1995b): Automation of the social interaction test by a video tracking system: Behavioural effects of repeated phencyclidine treatment. J Neurosci Meth 59: $157-168$ 
Sams-Dodd F (1996): Phencyclidine-induced stereotyped behaviour and social isolation in the rat: A possible animal model of schizophrenia. Behav Pharmacol 7:3-23

Sams-Dodd F (1997): Effect of novel antipsychotic drugs on PCP-induced stereotyped behaviour and social isolation in the rat social interaction test. Behav Pharmacol 8:196-215

Sams-Dodd F, Newman JD (1997): Effects of administration regime on the psychotomimetic properties of d-amphetamine in the squirrel monkey (Saimiri sciureus). Pharmacol Biochem Behav 56:471-480

Scaggs PR, Ridley RM (1979): The effects of dopamine and noradrenaline blockade on amphetamine-induced behavior in the marmoset. Psychopharmacology 62:41-45
Schiörring E (1997): Changes in individual and social behavior by amphetamine and related compounds in monkeys and man. In Ellinwood EH, Kilbey MM (eds), Cocaine and Other Stimulants. New York, Plenum Press, pp. 481-522

Siegel RK (1978): Phencyclidine and ketamine intoxication a study of 4 populations of recreational users. In Peterson RC, Stillman RC (eds), National Institute of Drug Abuse Research Monograph \#21. Washington DC, NIH Press, pp. 119-147

Snyder SH (1973): Amphetamine psychosis: A "model" schizophrenia mediated by catecholamines. Am J Psychiatr 130:61-67 